\title{
Valuation Methodology for Technology Developed at Academic R\&D Groups
}

\author{
L.R. Vega-González*¹, J.M. Saniger Blesa ${ }^{2}$ \\ ${ }^{1}$ Coordinación de Vinculación y Gestión Tecnológica, Centro de Ciencias \\ Aplicadas y Desarrollo Tecnológico, CCADET-UNAM, México \\ *roberto.vega@ccadet.unam.mx; (55) 56228626 \\ 2 Materials \& Nanotechnology Group CCADET-UNAM México, \\ jose.saniger@ccadet.unam.mx; (55) 56228601
}

\begin{abstract}
Abstract

This work refers to technology embodied as devices, equipment, software or processes primarily developed at universities in developing countries for research or teaching. Sometimes it is also as the result of externally financed projects contracted with industry. Nearly always technology developed at academic R\&D groups results in laboratory prototypes. When it is required to define the technology transfer (TT) contract terms for the license of the university patrimonial rights to external funding companies or other interested parties, a question arises: what is the monetary value? In this paper we present a four-step method for technology valuation based on the identification of specific value points (SVP) related to its development. The final technology value must be within previously defined value limits. The presented methodology is actually being used to valuate some devices developed at the Centro de Ciencias Aplicadas y Desarrollo Tecnológico (CCADET) of the Universidad Nacional Autónoma de México (UNAM).
\end{abstract}

Keywords: precompetitive technology valuation, technology transfer, developing countries universities

\section{RESUMEN}

Este trabajo se refiere a la tecnología que toma la forma de dispositivos, equipo, software o procesos desarrollados en universidades de países en vías de desarrollo para enseñanza e investigación. Algunas veces también es el resultado de proyectos financiados externamente por medio de contratos con la industria. Casi siempre la tecnología desarrollada en las universidades toma la forma de prototipos de laboratorio. Cuando se requiere definir los términos de los contratos de transferencia de tecnología para licenciar los derechos patrimoniales universitarios a las empresas patrocinadoras o a otras interesadas, aparece una pregunta: ¿cuál es el valor de la tecnología? En este artículo se presenta un método de cuatro pasos para la valuación de tecnología basado en la identificación de puntos de valor específico (SVP, por sus siglas en inglés). El valor final de la tecnología debe estar dentro de límites previamente definidos. La metodología presentada es usada actualmente para valuar algunos dispositivos desarrollados en el Centro de Ciencias Aplicadas y Desarrollo Tecnológico (CCADET) de la Universidad Nacional Autónoma de México (UNAM).

\section{Introduction and Literature Review}

The process of technology development at university starts with the transformation of basic knowledge into physical academic, concept or laboratory prototypes, including the know-how to do them and in some cases the actions taken to obtain industrial property certificates. Later, there comes the technology transfer (TT) from universities and research and development institutions to industrial firms. After the technology developed at academic R\&D groups is transferred to firms, it is transformed in tangible assets as products, operation protocols, processes and services that will be launched to market. At this time other intangible assets are created and firms frequently obtain new industrial property certificates. Intangible assets have been identified as the most critical resource of today's business enterprise. 


\begin{tabular}{|c|c|c|c|}
\hline Method & Scope & Major Advantages & Major disadvantages \\
\hline Intuitive & Basic Value idea & Easy and prompt calculations & With no fundamentals \\
\hline Cost & $\begin{array}{l}\text { Reproduction and } \\
\text { Replacement Cost }\end{array}$ & $\begin{array}{l}\text { Idea of minimum value given. } \\
\text { Information available and reliable. } \\
\text { Economic principle of substitution. } \\
\text { Monetary Value }\end{array}$ & $\begin{array}{l}\text { Future earnings of asset not reflected. } \\
\text { Explicit assumption expenditures in } \\
\text { prototypes should always create value }\end{array}$ \\
\hline Market & $\begin{array}{l}\text { Find the value of } \\
\text { the asset from } \\
\text { sales comparison }\end{array}$ & $\begin{array}{l}\text { Practical and logical method applicable to } \\
\text { all type of intangible assets. Most direct } \\
\text { method. } \\
\text { Economic principles of competition and } \\
\text { equilibrium. } \\
\text { Monetary Value }\end{array}$ & $\begin{array}{l}\text { Most technological assets are not traded } \\
\text { frequently enough to establish } \\
\text { comparisons. } \\
\text { The intangible assets are commonly } \\
\text { traded within a business and is difficult to } \\
\text { disassociate them from the business }\end{array}$ \\
\hline Income & $\begin{array}{l}\text { Find the value of } \\
\text { the asset starting } \\
\text { from the appraisal } \\
\text { of the future } \\
\text { benefits } \\
\text { associated. }\end{array}$ & $\begin{array}{l}\text { Elements such as income generating } \\
\text { capacity, appropriate cost of capital and } \\
\text { risk associated with the asset are made } \\
\text { explicit, while in other methods are } \\
\text { implicit. Well known and widely } \\
\text { recognized method. } \\
\text { Based on economic principle of } \\
\text { expectation. Monetary Value }\end{array}$ & $\begin{array}{l}\text { The projection of the future net cash } \\
\text { flows is difficult. The estimation of the } \\
\text { actualization rate is complicated since it } \\
\text { has to consider not only the cost of } \\
\text { capital but also the risk associated to the } \\
\text { intangible asset. } \\
\text { The required data and information need } \\
\text { to be estimated. }\end{array}$ \\
\hline $\begin{array}{l}\text { Real } \\
\text { Options }\end{array}$ & $\begin{array}{l}\text { Find the value of } \\
\text { the asset starting } \\
\text { from the appraisal } \\
\text { of future benefits. }\end{array}$ & $\begin{array}{l}\text { Most complete method, considers } \\
\text { uncertainty and variability in future } \\
\text { outcomes. It is an extension of the } \\
\text { Incomes method but considers the } \\
\text { specific operating environment in which } \\
\text { the technology is exploited. }\end{array}$ & $\begin{array}{l}\text { Option calculation uses a complex } \\
\text { formula. Uncertainty is difficult to } \\
\text { estimate }\end{array}$ \\
\hline
\end{tabular}

Table 1 Technology valuation methods. 
The definition of an intangible asset is a resource that does not have a physical embodiment and whose industrial and economic exploitation gives a claim to a future benefit (Bouteiller, 2000; Smith and Parr, 2000; Lev, 2001).

A basic input for the TT process is to know what the value is but nearly always the valuator has trouble identifying what the best approach to valuing intangibles is. In this work, we present a methodology for valuation of both tangible and intangible assets, based in the most common approaches available in the current technology valuation literature: (a) intangible assets valuation, (b) monetary value models, (c) cost, market and risk approach, (d) real options financial models, (e) contingency valuation models and (f) pragmatic models. Table 1 shows an actual comprehensive classification of technology valuation methodologies according to the most recent literature review. (Chiesa et al. (op. cit); Park \& Park, 2004).

\section{(a) Intangible Assets Valuation}

The problem for valuing a technological asset arises when organizations are involved in decisions concerning not only the external acquisition of technology, but also the opportunity to sell or cooperate. (Andreou et. al., 2007). Whatever the form of the transaction, the valuation of intangible assets represents a common and relevant problem. (Chiesa,\& Gilardoni, 2005). The problem increases when the valuation of the corporate knowledge for purposes of transferring, sharing or licensing it is required. (Contractor, 2000). For trading and transfer negotiation purposes market technology is the knowledge which is valuable as an asset and is identified as an intangible asset; it includes patent rights, trade secrets, know-how, computer software, database, products, devices, operations guides, trademarks, industrial designs, etc. (DongHyun et. al., 2007). (b) Monetary Value Models

Boer, (1999, p. X) suggests that in the technology marketplace a value range determined by monetary financial criteria is a useful starting point for both sellers and buyers. The Discounted Cash Flow (DCF) is the widest spread methodology and is based in the income approach or the sales revenues. The identification of relevant cash flows is the starting point for all valuation issues, and indeed for any financial business decision (Drury, 2004, Chapter 9). DCF methods are generally used to generate Net Present Value (NPV) of technology. DCF is also used for the valuation of patents on cost production process improvements based in obtaining the relevant information needed to estimate cash flows. (Van Triest \& Wim, 2006).

\section{(c) Cost, Market and Risk Approach}

According to Boer (2004, pp.1), the two basic building blocks for calculating the value of technology are the DCF calculation and the cost of capital. The Cost Approach is based in the economic principle of substitution that postulates that a prudent buyer would pay no more and a willing seller could command no more for a technology that the cost to create an intellectual asset of equal desirability and utility. Costs are divided in reproduction cost and replacement cost. The market approach argues that the technology value is equivalent to what others in the market place have judged it to be. (Park \& Park, 2004). A different perspective is when a buyer invests in advanced technology because opportunity costs appear involved in the process. Orduobadi (2007) presented a list of potential costs due to risk of new technology adoption.

\section{(d) Real Options Financial Models}

The Real Options Analysis is a truly extension to the Discounted Cash Flow Analysis; next to expected cash flows, the essential ingredient is the standard deviation or volatility of those expected cash flows. The problem then is that patents on specific technology are non traded 
assets, implying that there are not market based estimates of the volatility. This makes an optionbased approach to valuing difficult patents. (Copeland \& Tufano, 2004; Zettl, 2002).

According with Mitchell \& Hamilton (1996), the Real Options Analysis ranges from intuitive judgment to very complex models. A firm invests in two types of operating options, growth options and operating options, real options models are mainly interested in technology investments embedding operating options looking to minimize risk. (Benaroch, 2001); Garlappi, 2001).

Real option valuation models are strongly based in business games and simulation and consider the managerial flexibility to make ongoing decisions regarding implementation of investment projects and deployment of real assets. (Cobb \& Charnes, 2003).

\section{(e) Contingent Valuation Models}

The Contingency Valuation Model (CVM) is a survey-based hypothetical and direct method to determine monetary valuations of the effects of technologies. These models are frequently used in the field of technology assessment. For example, within the Cost Benefit Analysis (CBA) applied to the economic valuation of health care technologies, there are two approaches to assign monetary values to life and health: (a) determination of human capital and (b) the indirect cost of disease by a person's contribution to the gross domestic product measured by wage rates. (Klose, 1999).

\section{(f) Pragmatic Models}

This valuation method is based in the consideration that the price of anything is an agreement to close a transaction between two counterparties, an expert's indicative estimate of what a fair value of something should be. (Muniesa, 2007). Prices can be found or proposed studying human behavior, since willingness to pay
(WTP) for a technology expresses a preference approach (Johannesson, et al., 1996). Price proposal is frequently combined with scoring for many different applications and technology valuation cases. (Chun-The \& Ching-Torgn, 2007). Scoring is based in obtaining a list of variables for the technology attractiveness and the subjective scoring qualification of them.

\section{The technology valuation problem at UNAM}

Public and private organizations today compete fiercely for survival and growth within the global market. Searching for innovation, enterprises get involved not only in buying external technology but also in selling or cooperating with other firms for technology development decisions. Whatever the form of transaction, the valuation of technology and, in general, of the intangible assets, represents a common and relevant problem, (Chiesa, et al., op. cit). Technology development, valuation and negotiation are part of the innovation process; there are big differences in the form this process is carried out in developed and developing countries. In the first case, there are intensive relationships between universities and industry while developing countries have been building R\&D institutions as isolated islands without establishing proper mechanisms for linking research institutes, universities and industry. (Awny, 2005).

In the case of Universidad Nacional Autónoma de México (UNAM), the institution's main objectives are the formation of human resources, research and cultural diffusion. Intensive R\&D efforts take place within the subsystem of research institutes and centers while faculties and schools also perform research related to teaching and the demonstration of basic principles in physics, chemistry, engineering and medical and biological sciences, among other fields. Very high quality results have been generated in the fields of basic science and technology development at UNAM 
(2004), with internal financing for experimental processes and teaching CCADET (2008). Technology is sometimes financed by industries through collaboration and technology development specific contracts, and is usually embodied in the form of laboratory prototypes once they are completed and tested. The university obtains the corresponding patents, copyrights and trademarks, which add to its patrimonial rights. Generally speaking, university technology is in the field of incremental innovation since it is mainly directed towards the improvement of technology performance and product feature enhancements. (Hacklin et. al., 2004).

After development, enterprises must sign technology transfer (TT) contracts to acquire technology commercialization rights. In order to negotiate TT contract terms, both the technology buyer and seller need to answer the question: how much does the technology cost? The valuation process is not simple and not always systematic, but multifaceted and multivariable; it nearly always depends on the valuator's perception. In the literature, it is well known that there are several critical success factors for the innovation process, including access to external knowledge and technology suppliers and the efficient technology administration of collaborations or technological alliances. (Andreou et. al., op. cit). The innovation process also depends on good valuation procedures. Generally speaking, we could say that for the technology developer, valuation must be done keeping in mind a cost perspective; while a benefits perspective is required for the buyer. In all cases, it is necessary to include at least three types of cost/benefit components: (a) tangible, (b) intangible, and (c) opportunity.

\subsection{Organizational assets}

Profit organizations' tangible assets are, among others: social capital, infrastructure, equipment, instrumentation and available technology, bank accounts, and any other asset included in their finance statements. In non-profit organizations such as universities, schools and R\&D institutions, the main tangible assets are the infrastructure and the laboratory equipment they possess. Nevertheless, they develop finance and accounting statements using similar methodologies to those used by profit enterprises and the reports obtained are not accurate since the economic resources come from governmental subsidy.

Table 2 shows the intangible assets for profit and non-profit organizations, developed from the Financial Accounting Standards Board classification, Holzmann cited by Chiesa (op cit) including Huang's (1997), intellectual capital intangible assets classification.

An organization's intellectual capital assets consist of two knowledge types: tacit and explicit. Tacit knowledge is mostly intangible since it is closely related to the empirical experience and capacities of working personnel and project teams. Explicit knowledge is more embodied, taking the form of intellectual property titles and certificates, calculation records, blueprints, pre-competitive and competitive technology. However, unless explicit knowledge connected with it has been previously traded and exploited, it has an intangible value. A close determination of the organization's intangible asset value could be obtained by the determination of the company's intellectual property rights and its pre-competitive and competitive technology value. (Contractor, op. cit). 


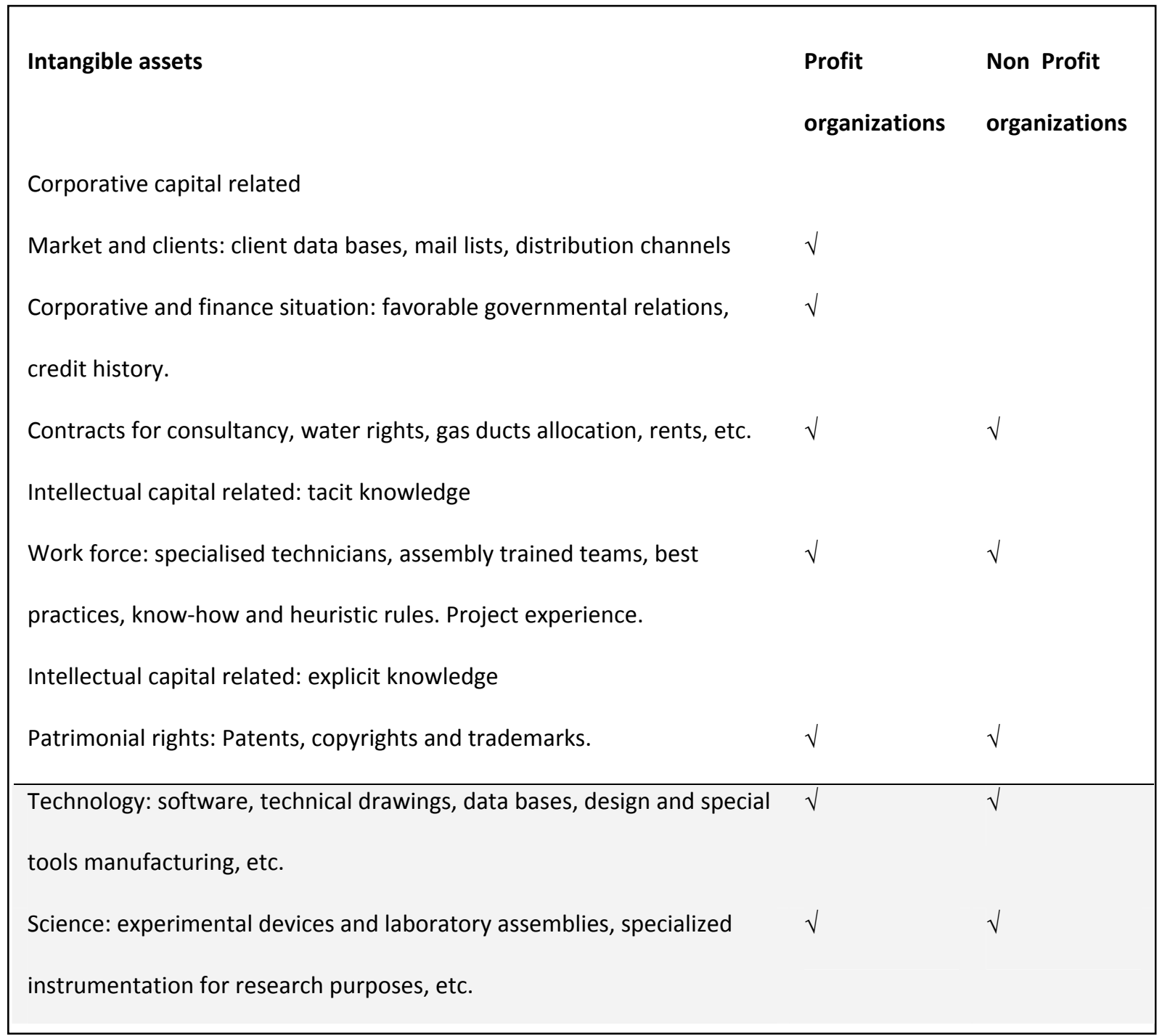

Table 2. Intangible assets classification. Modified from Holzmann in Chiesa (op cit).

\section{Technology developed at Academic R\&D Groups}

Fig. 1 shows a project life cycle. ${ }^{1}$ It begins with the preliminary market needs information plus the

1 We consider a typical innovation and technology development project, the one realized between universities R\&D institutes, centers and small and medium-sized firms, since this is the common case in developing countries. Projects developed by big enterprises are not typical because they have their own R\&D, manufacturing and marketing capacities. The objective of an innovation and technology development project is to develop a final commercial product. previous Basic Research Groups knowledge. Mixing those elements with the technological development capabilities of the organization's technical people, an initial technological product concept is achieved. This is the origin of the process; technological development projects are different from conventional engineering projects since they begin from solution ideas or concepts, not with well structured specifications. 
Based on the preliminary concept, the applied research and technology development stage known as the Concept Testing Stage begins. This stage's objective is to apply the university R\&D institution's basic knowledge and know-how to generate functional technological prototypes in order to test the validity of the concept with the aim of responding to specific and well determined needs of society and industry. This is a very important step since there is nearly always a gap between the university's research focus and the society's product needs. In developed countries such as Japan, there are cooperative organizations at the industrial level, known as Concept Testing Laboratories focused on realizing product concept testing validations, sponsored by the associated enterprises, which in return receive a number of different services such as consultancy, technology tools, testing and measurement and manufacturing equipment among other things required for the successful operation of their facilities, (Fair \& Freedman, 1991). Another example of shared pre-competitive research is the USA Edison Welding Institute, an independent non-profit organization that offers a range of services and expertise to the American welding industry. Despite having cooperative funding, the results of the projects are strictly confidential to the sponsor for competitive purposes. (Moore, 1986).

At universities in developing countries, concept testing validation must be done by the R\&D centers and institutes through the iterative development of prototypes up to the point of getting a functional technology. Therefore, technology is obtained by applying the R\&D activities and procedures shown in the last two rows of Table I. When the concept is validated, a new prototype development and validation stage, the pre-commercial stage, begins. The technology prototype range is then defined as the stage between the functional concept prototypes and the pre-commercial laboratory scale technology.
Physical prototypes turn intangible knowledge assets into tangible assets at the end of the precommercial stage since they are embodied in the physical form of the first version of the technology product idea.

All of the technology development stages require external financing. That means a negative capital flow $(-\$)$ that must be considered as an investment. According to Goldsmith and Foxall (2003), innovativeness is the entrepreneur's attitude towards innovation. In small companies in developing countries, entrepreneurs frequently consider R\&D as expenditure. Nevertheless, after a product is in the market and becomes an innovation, a positive capital flow return (+\$) comes with growing sales, until the technology matures and declines.

The early stages of development are shown in more detail in Fig. 2. The thick line below the timeline in Figure 1 shows an apparently endless iterative process for the pre-competitive prototype development. We understand the iterative design processes as technology learning loops, adapting the term used by Sheasley (2000) referring to research learning loops. The origin of the project development process is Stage " 0 ". It is the contact point between the addressed society and market needs and the completely intangible organization assets in the form of technical capabilities and available $R \& D$ academic groups. It is likely that the developing institution already has awarded patents, copyrights and trademarks related to the technology development problem under consideration.

The institution's leadership will decide to work on the innovation project depending on its development plan strategy. The following are the most common reasons: (a) when the project is contracted and financed by an external company. (b) when the technology to be developed will help support ongoing basic research projects (c) when 
the technology is required to accomplish maintenance work (d) when the project is requested for governmental agencies to solve high impact society needs, (e) when the prototypes are required for teaching purposes, (f) others. Once the decision is made and the agreements are signed, the university's R\&D groups in conjunction with the external party, work on the concept development. Once the concept technological solution is on the table, the university integrates its scientific knowledge in the form of R\&D protocols and its technological know-how to develop a functional prototype that proves the concept.

The Concept prototype is the result of Stage "1" and is a little more tangible, but still moneyconsuming in the form of materials, testing equipment and technical labor costs. Frequently, the electronic cards and the mechanical, optical, acoustic and sensor assemblies of a university's concept prototypes are weakly supported by improvised structures and interconnected with bunches of wires. The inputs and outputs frequently have no screwed terminals and are interconnected to the devices trough twisted pairs of wires. The display used is sometimes borrowed from another experiment and lacks accuracy, precision and calibration.

Generally speaking, they are artisan or handmade prototypes. Software programs in $\alpha$ version are also considered as concept prototypes.

The working space between Stages " 1 " and " 2 " is conformed of hard and expensive activities. Science groups offer many different experimental laboratory mountings and the technical personnel work intensively to obtain an improved bench version prototype. With each new improved prototype version, the technology assets acquire more features and tangibility. There is much iteration in the development of prototypes; this is represented with circles and two arrows in Fig 2.

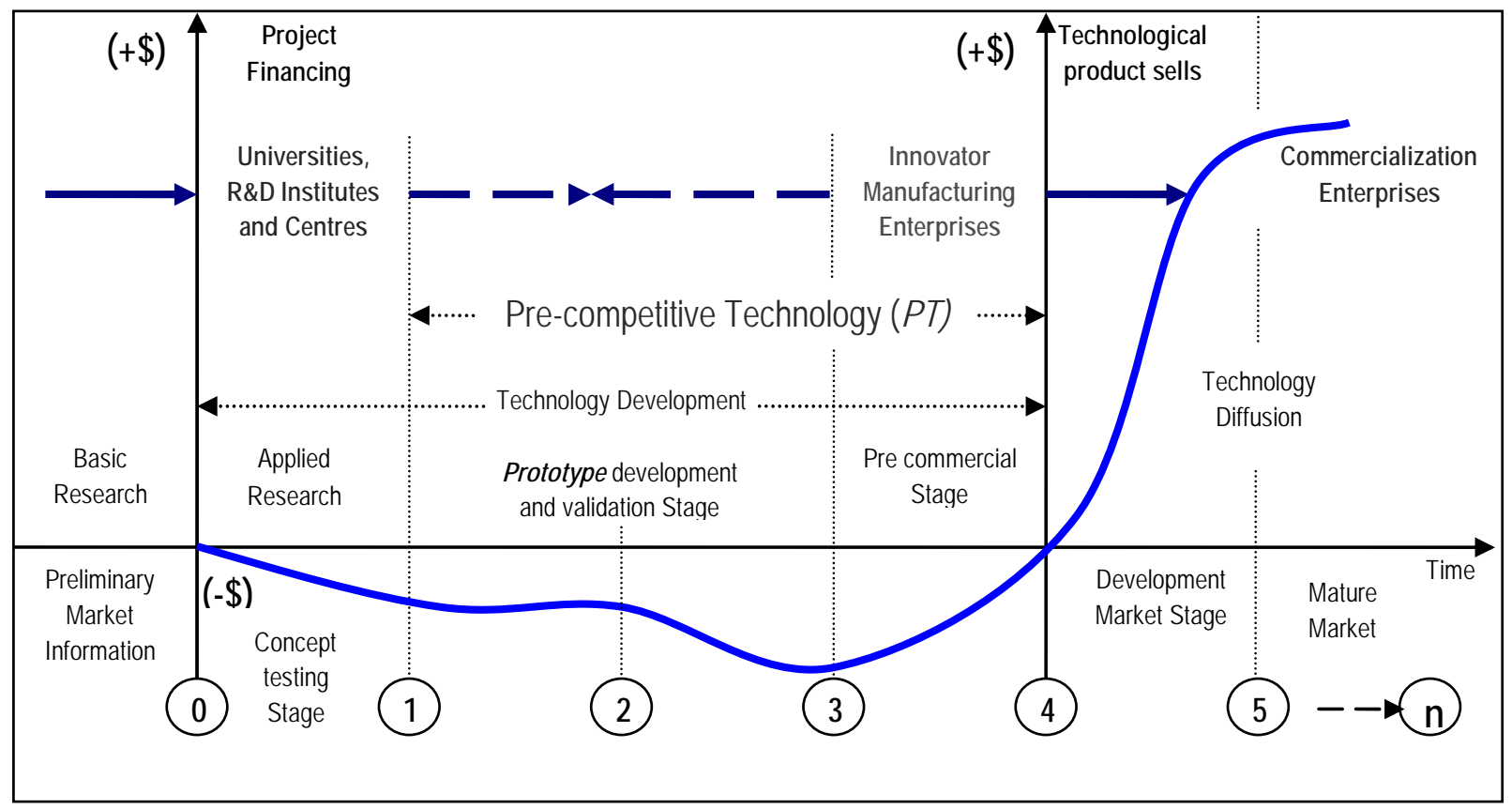

Figure 1. Technology developed at Academic R\&D Groups life cycle. 


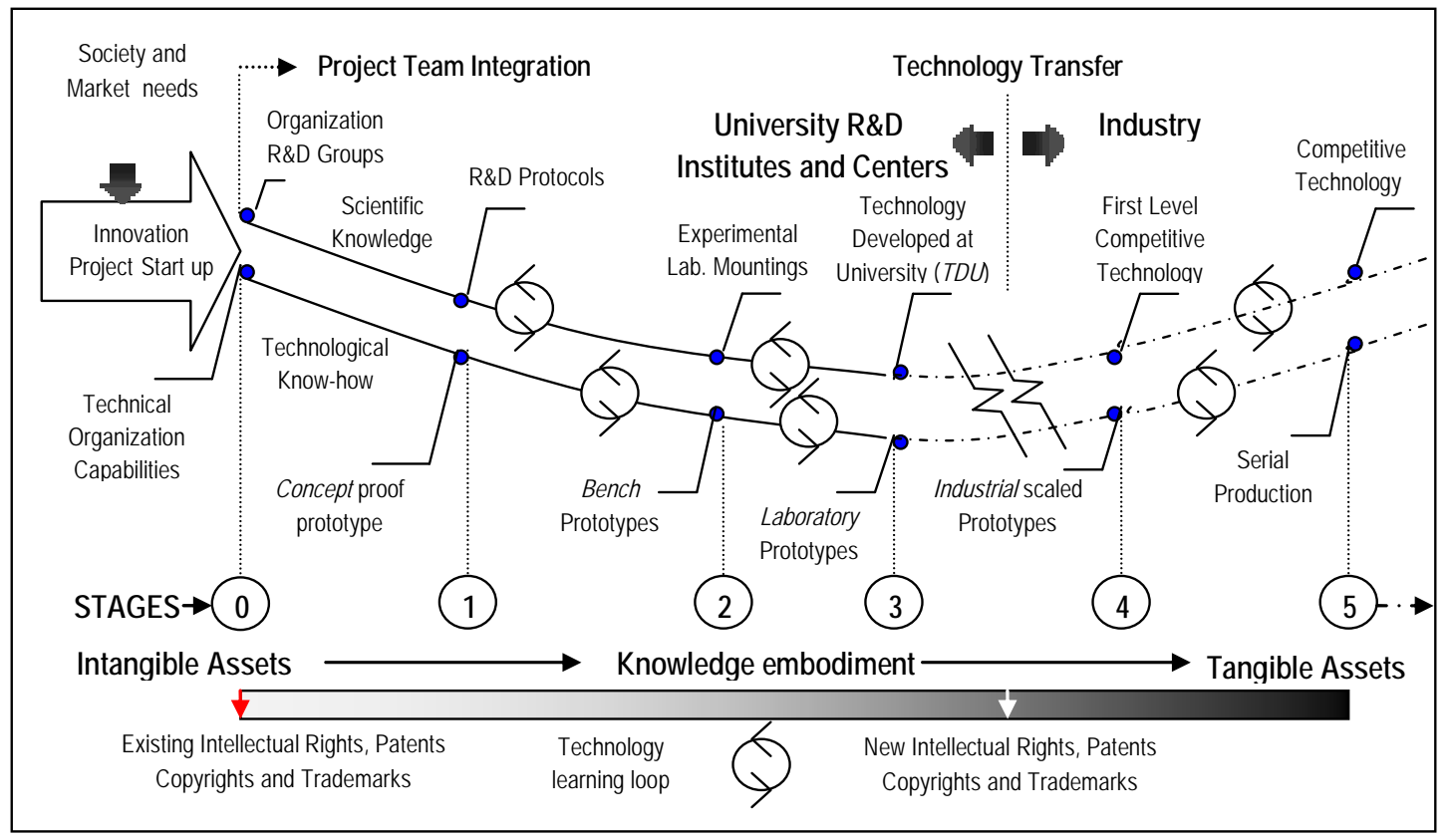

Figure 2. Technology based assets in the development stages.

This means that several activities become repetitive as shown in Fig. 3. The assembly, calibration, testing, engineering and design modifications are done several times before obtaining a prototype. This process could take months or even years, depending on the project's complexity and the availability of the materials and required resources.

At the end of Stage " 2 ", the project team has a bench prototype. Bench prototypes are frequently the result of internal research projects, devices used in maintenance or teaching and curiosity among many other academic activities; for that reason, they are the most common kind of prototype at universities in developing countries. Bench prototypes are better than concept prototypes and are considered a low grade precompetitive technology. As shown in Fig. 3, they include modifications to the mechanical, electric, optical, and acoustic and sensor assemblies. The project team should also include improved electronic cards and robust mountings. The calibration and testing is better done using high precision and accurate measurement equipment. Software programs in $\beta$ version are considered bench prototypes. To get a complete precompetitive technology, it is necessary to run the way between Stages " 2 " and " 3 ". The project team must then work on new features and specifications and an extended project engineering and design group must work on the device usability, reliability, availability, and on improving the device's housing and display.

At the output of Stage " 3 ", there is a full Technology Developed at University (TDU): the Laboratory prototype. Generally speaking, this is the end of the university R\&D team's intervention in the innovation project.

When the technology developed is financed and required by an external organization, the next step is the technology transfer negotiation. 
A valuation of the technology is required before defining the contract terms. Once the transaction is realized, technology becomes a totally tangible asset, it can be reported in the company's finance yearly reports and is subject to audit.

For the university, the acquired knowledge increases the yearly intellectual capital report indexes, (Karlz-Heinz et. al., 2002). The external organization that receives TDU will work on scaling the laboratory prototype to get an industrial-scale prototype which, in turn, will be a first level competitive technology. This is an industrial field known as new product development (NPD). The technology is first transferred to a design team for a product design with material and component specifications including constructive blueprints. This information is later passed to the manufacturing group which, in turn, generates a first product prototype. The market development stage then begins, which is required in order to fulfill the market and society needs when technology achieves maturity, as shown in Figure 1. The entire sequential NPD process described here has been referred to as a relay race and has been used internationally in the 1980s and early 1990s. Nowadays, the concurrent development strategy is in full use according to Cooper and Gaynor, cited by McDermott \& Handfield (2000).

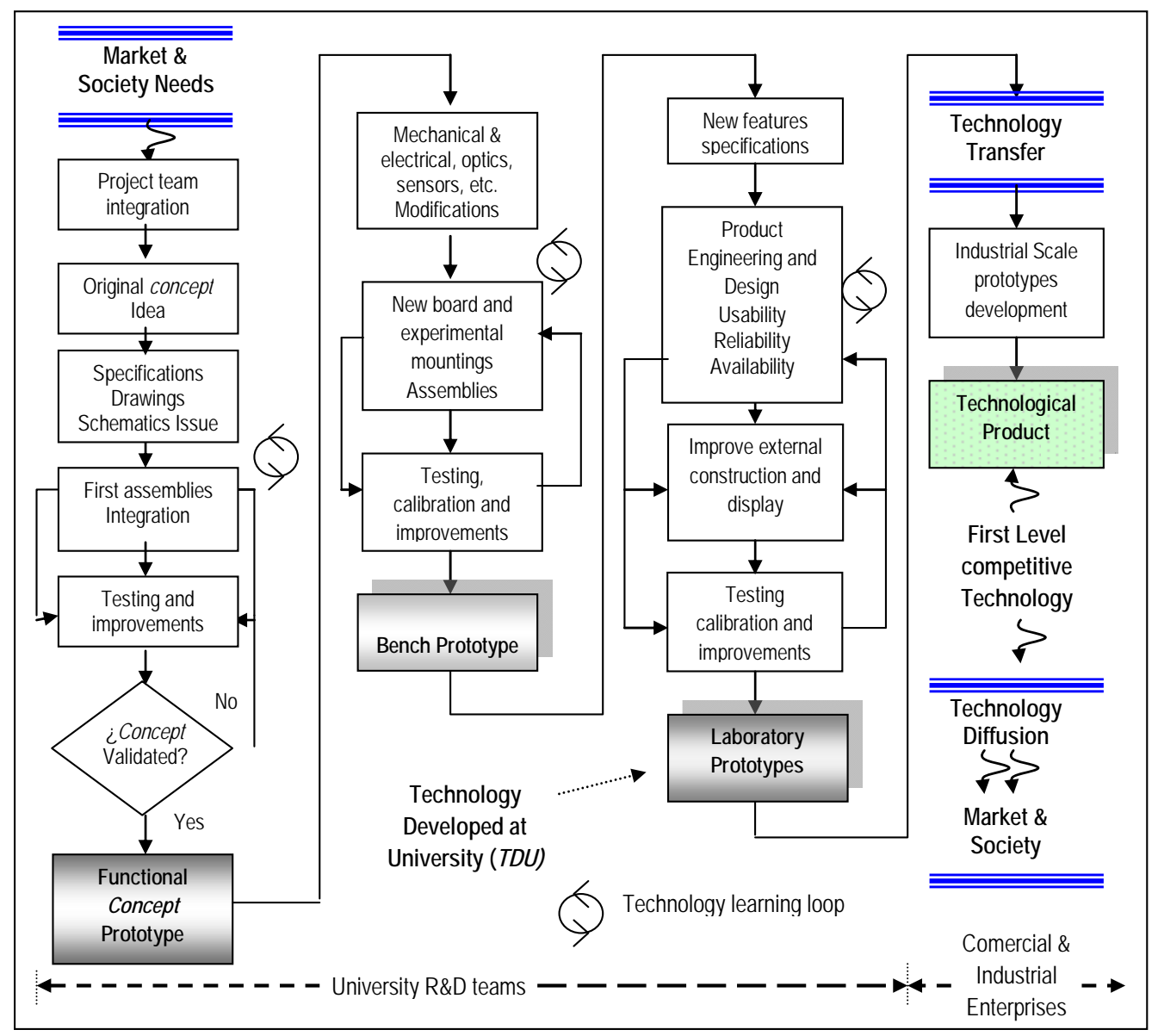

Figure 3. Integral block diagram for a technology development project. 


\section{Valuation Methodology framework}

As we have seen before, technology is frequently embodied in human knowledge or in physical assets and, therefore, is not always visible nor is tangible, which implies that technology valuation is a subjective activity. The value of technology is expressed in terms of a score, index or monetary value. Our purpose here is to measure the monetary worth of technology or its monetary value. The scope of a full functional technology the specific valuation points (SVPs) in the technology life cycle.

\subsection{Building the Technology Value}

In order to build the technology value, we first need to identify where the SVPss that add value to the technology in the innovation and project development process are. Beginning at the left of

Fig. 4, we find five intangible organization assets that add value to the technology.

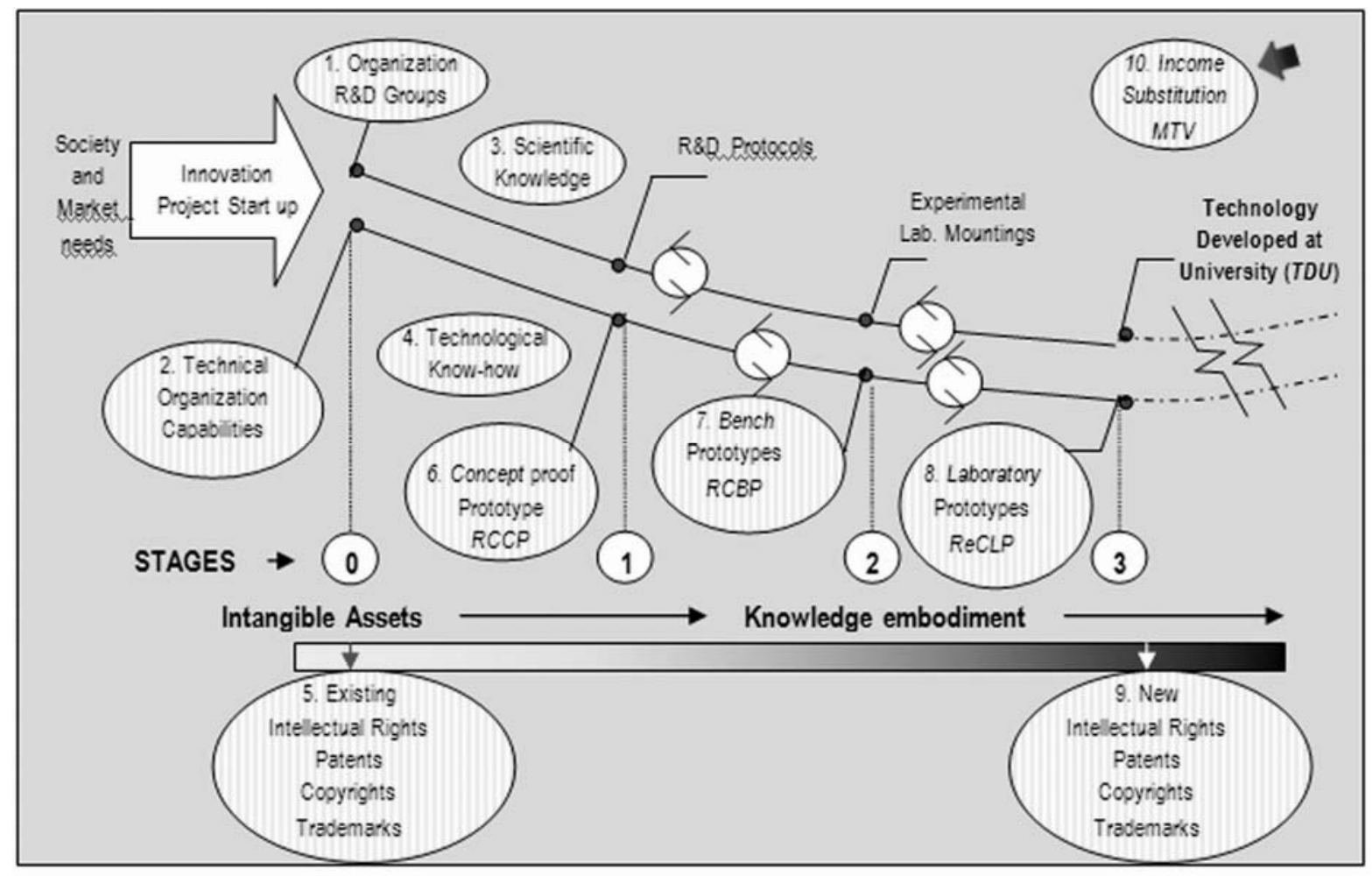

Figure 4. Specific valuating points identified in technology development life cycle

comprises the concept, bench and laboratory prototypes. For that reason, the pre-competitive technology valuation method presented in this paper is useful in understanding the first three project development stages presented earlier. Valuation of technology will require the consideration of tangible and intangible assets identified in each development Stage. Fig. 4 shows
According to the classification in Table 1, the R\&D Groups, SPV 1, and the technical experts' capabilities, SPV 2 are part of the project team and, therefore, indicators of the organization's tacit knowledge. Scientific knowledge SPV 3, technology know-how, SPV 4, and the existing intellectual property rights, SPV 5, used and available for the project development are explicit 
knowledge. SPV 6, 7 and 8 are related to the construction costs of concept, bench and laboratory prototypes. SPV 9 refers to new intellectual property rights obtained for the results at the end of the project. Finally SPV 10, shown at the right upper end of Fig. 4 represents an indirect measurement or assumption of the possible commercial trade of the technology.

The valuation method should express the monetary value of each of the SVPs shown. For that purpose, we will use the combination of several methods included in Table $\mathbf{1}$ and some pragmatic market price considerations for the technologies. (Muniesa, 2007).

\subsection{Calculation of Base Technology Value with the Cost approach}

The cost method is usually used when technology is at such an early stage of development that its market application is still unclear. The level of uncertainty is higher and the knowledge of future business is very limited. The first consideration must be the measurement of the expenditure necessary to create and develop the technology asset.

The cost method must be applied to Stages "1", " 2 " and " 3 " since it is based on the economic principle of substitution in which a prudent investor would pay no more for a technological asset than it would cost to create or acquire a similar asset. The exercise is to calculate, first, the reproduction cost that includes the construction of an exact replica of the concept and bench prototypes and, later, to calculate the replacement cost until a laboratory prototype is obtained. Since the cost approach does not measure the technology's wealth creating potential, but does consider historic costs, the reconstruction and replacement prototype costs just give us the base technology value. Fig. 5

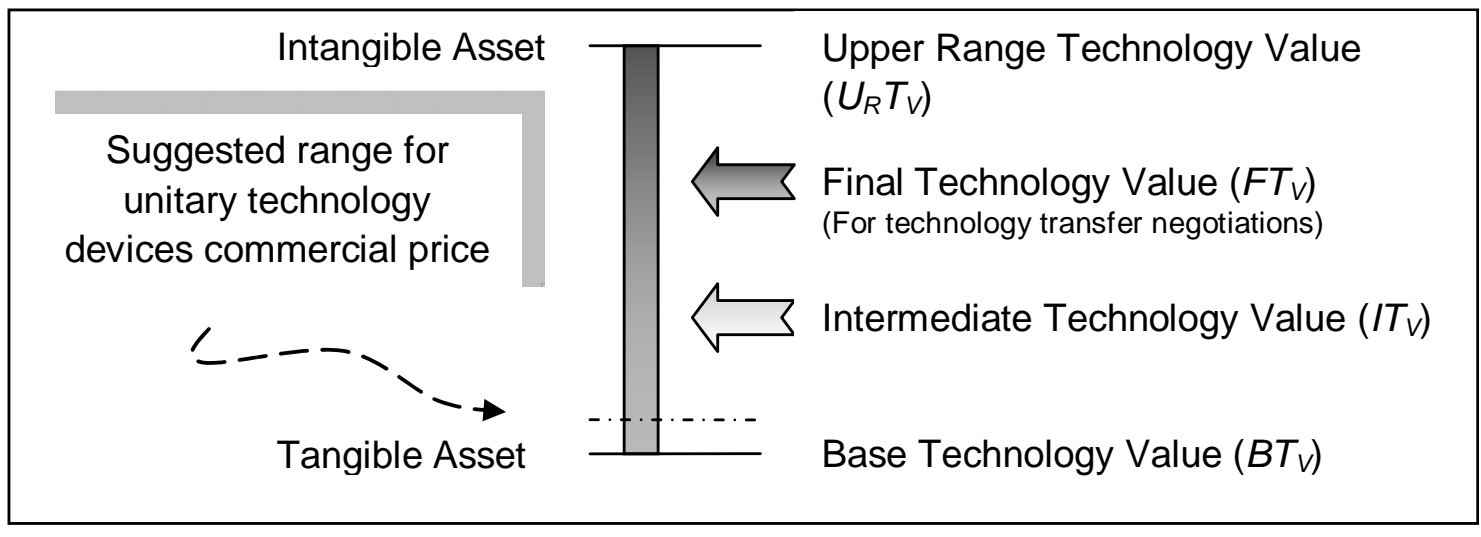

Figure 5. Technology Value Scale.

The technology value base is then obtained by calculating (6), (7) and (8) SVPs.

$$
B T_{V}=R C C P+R C B P+\operatorname{Re} C L P
$$


Where

$\mathrm{RCCP}=$ Reproduction Cost of concept prototype, (SVP 6)

RCBP = Reproduction Cost of bench prototype, (SVP 7)

ReCLP = Replacement Cost of laboratory

prototype, (SVP 8)

The $B T_{V}$ is a fundamental variable for the valuation method.

4.3 Calculation of the Upper Range Technology Value $\left(U_{R} T v\right)$ with a Market method

For precompetitive technologies, $U_{R} T_{V}$ can be determined using one of two options: (a) when information about recent licensee contract terms is available for a similar technology, it can be taken as a simple and direct benchmark and can be used to obtain SVP 10; (b) if benchmark technology transfer information is not available, the valuator can use a combination of intuitive and projected income methods for determining $U_{R} T_{V}$ We suggest using the value of a medium scenario sales year, taking the commercial price of a similar technology available at market value.

The objective of the market approach is to obtain an expected monetary value based on technology substitution. It argues that the value of a technology is equivalent to what others in the marketplace have judged it to be. The prerequisite is the existence of an active public market and transaction data for comparable properties. When public price and comparability information are available, they can be used for assigning the upper range technology value $\left(U_{R} T_{V}\right)$ Since there is not always enough information in developing countries, option (b) is the most probable case for precompetitive universitydeveloped technology.

\subsection{Estimation of the Intermediate Technology Value (ITV)}

To obtain the ITV value we address the intellectual rights intangible assets value (SVP 5 and 9) with intellectual property management techniques. Since the very substantial value of intangible assets (e. g. patents, trademarks, and brand recognition) is not accounted for on the balance sheets of most companies, (Breitzman \& Mogee, 2002), nor in Intellectual Capital Reports of R\&D organizations, (Karlz-Heinz \& Campbell, 2004), the alternative is to consider the possible wealth creation of the technology under valuation.

Historical diffusion behavior information becomes available when competitive technologies or technology products reach the market. The income approach can then be used to valuate the monetary value of existing and new property rights assets, calculating this value as a percentage of the profits expected to be generated during the product life cycle. The patent valuation requires relevant information to estimate cash flows and depends of the patent type, for example information on production process improvements, and there will be a necessary cost reduction that will impact the competitive advantage of the patent owner. As is frequently seen in the pharmaceutical industry, patent rights generate large amounts of cash flow bringing higher unit sales and higher prices for the sale of a medicine in a competitive market. However most patents only cover a part of a product or service and a very small part of a production process. (Van Triest \& Vis, 2006).

In the case of technology developed by academic R\&D Groups, there is not enough market information, and only sales expectation exists for estimating wealth generation. For the estimation, the valuator could forecast the commercial return using a technology life cycle of five years maximum and calculating three scenarios: (a) high growth sales profile, using a straight line with large slope for increasing sales; (b) medium growth sales profile, using a straight line with medium slope for increasing sales; and, (c) low growth sales profile, using a straight line with a 
low slope for increasing sales. We, as Sheasley (op. cit.), recognize that valuation of intellectual assets in their early stage of discovery must rely on people's judgment; therefore, we suggest calculating $I T_{V}$ as $20 \%$ of the five-year sales profit at present value with a medium growth sales profile. ITV can be considered to be the estimation of the monetary value of the technology's intellectual rights; SVP 5 \& SVP 9.

\subsection{Estimation of the Final Technology Value (FTv) Using a Scoring and Pragmatics Approach}

To obtain the Final Technology Value, $F T_{V}$, we shall include the intellectual rights value (IRV) and the estimation of the contribution of the organization's intellectual capital value (SVP 1, 2, 3 and 4).

$$
F T_{v}=I T_{v}+O I C_{s v}
$$

Where

$I T_{V}=I R_{V}=$ Intellectual Rights Value

$O I C_{S V}=$ Organization's Intellectual Capital Scoring Value

Finally, $F T_{v}$ will be the price that we shall use for technology developed by Academic R\&D Groups transfer contract negotiations. The price should permit an agreement between the counterparties, the university that develops the technology and the firm interested in production and commercialization. The meaning of pragmatics is that prices can be found or can be proposed. (Muniesa, op. cit.). The logic behind FTv estimation is that $I T_{V}$ must be increased by a scored estimation of an organization's intellectual capital value, SPV 1 to 4 . Pragmatics relies on the consideration that the precompetitive technology under valuation has behind it solid foundations and great backup. We propose to weight $B T_{V}$ for the calculation of OICsv and score it as follows:
$O I C_{s v}=k_{1} B T_{v}$

Where:

$\mathrm{K} 1=1$, if the organization has technical capabilities and experienced people

$\mathrm{K} 1=1.5$, if the organization has technical capabilities and technological know-how.

$\mathrm{K} 1=2$, if the organization has technical capabilities and technological know-how and also R\&D groups and scientific knowledge.

Finally:

$F T_{V}=I T_{V}+k_{1} B T_{V}$

\section{Conclusions}

Since no regulation or procedure exists for technology valuation, the decision maker's judgment is highly influential in the estimation of diverse parameters used in the valuation. Based on the identification of specific valuation points (SVPs) found along the technology's development process, the valuation methodology presented in this paper includes four main calculation steps: (a) determination of the technology's value range with a base value taken as the replacement and reproduction cost (SPV 6, 7 \& 8), (b) determination of the maximum technology value using a combination of intuitive and projected income methods or a price benchmark of similar technology (SPV 10), (c) price approximation of the patrimonial rights value as the sales income generation capacity (SPV 5 \& 9), and (d) to complement the valuation method subjectively score and weight the base technology value for pragmatically inclusion of the value contribution of the intellectual capital behind the technology (SPV 1, 2, 3 \& 4). In short, cost, market price and income are considered part of the expected return analysis and comprise the market value of the technology developed for Academic R\&D Groups 
(Park \& Park, op. cit.). For those technologies in more advanced development stages, the valuation method shall also include the technology contribution itself as an identification and quantification of the technology's position compared to the state of the art (Dong-Hyung et. al., op. cit).

The valuation method developed here has been applied to valuate a prototype of the TSHnInstantest electronic analyzer diagnostics system developed by the Electronics Academic Group for Laboratorios Silanes SA de CV, a prototype of a Scanning Probe Microscope (SPM) developed by the Microwaves and Photonics Academic Group and the Biology Learning Software for Elementary Schools developed by the Science Education Academic Group. All the academic groups belong to the Centro de Ciencias Aplicadas y Desarrollo Tecnológico (CCADET), at the Universidad Nacional Autónoma de México (UNAM). The technology valuation prices obtained have been used for technology transfer negotiations.

\section{References}

[1] Andreou, A. N., Green, A., Stankosky, M., (2007), A framework of intangible valuation areas and antecedents, Journal of Intellectual Capital, Vol. 8, No. 1, pp.52-75. Emeral Group Publishing Ltd.

[2] Awny M. M., (2005), Technology transfer and implementation processes in developing countries, International Journal of Technology Management, Vol. 32, Nos. 1/2, pp.213-220. Inderscience Enterprices Ltd.

[3] Benaroch, M., (2001), Option Based management of Technology Investment Risk. IEEE Transactions on Engineering Management. Vol. 48 No. 4, pp.428-444.

[4] Boer, F. P., (1999), The valuation of technology: Business and financial Issues in R\&D. John Wiley \& Sons.

[5] Boer, F. P., (2004), Technology valuation solutions. John Wiley \& Sons.

[6] Bouteiller, C., (2000), The evaluation of intangibles: advocating for an option based approach. Alternative Perspective on Financing and Accountings Conference, Hamburg.

[7] Breitzman, A. F., Mogee, M. E., (2002), The many applications of patent analysis, Journal of Information Science, Vol. 28. No. 3; pp. 187-205.

[8] Centro de Ciencias Aplicadas y Desarrollo Tecnológico, CCADET, available at http//:www.ccadet.unam.mx, (retrieved 10 july 2008)

[9] Chiesa, V., Gilardoni E., Manzini, R., (2005), The valuation of technology in buy-cooperate sell decisions, European Journal of Innovation Management. Vol. 8, No. 2; pp 157-181. Emerald Group Publishing Ltd.

[10] Chun-The, L., Ching-Torgn, L., (2007), Application oriented Technology Valuation: examples from the semiconductor Industry, Proceedings of the Industrial Electric \& Electronics IEEE, IEEM., pp. 2006-2009.

[11] Cobb, B. R., Charnes, J. M., (2003), Simulation and optimization for Real Options Valuation. Preceedings of the Winter Simulation Conference. S. Chick, P. J. Sánchez, D. Ferrin and D. J. Morrice, eds. 
[12] Contractor, F. J., (2000), Valuing Corporate Knowledge and Intangible Assets: some general principles. Knowledge and Process Management. Vol. 7; No. 4 ; pp. 242-255.

[13] Copeland, T., Tufano, P., ( 2004), A real world way to manage real options. Harvard Business Review, Vol. 80, pp.90-99.

[14] Dong-Hyung B., Wonsik S., Kil-Pyo H., (2007), A technology valuation model to support technology transfer negotiations, R\&D Management. Vol. 37, No. 2; pp.123-138. Blackwell Publishing Ltd.

[15] Drury, C., (2004), Management and Cost Accounting, Sixth ed. Thompson, London.

[16] Fair, B. R., Freedman J. F., (1991), Technology Transfer utilizing the Proof of Concept Facility. IEEE/SEMI Advanced Semiconductor Manufacturing Conference, CH3042-9/0000-066; pp. 66-68.

[17] Faulí-Oller, R., Sandonis, J., (2002), Welfare Reducing Licensing. Games and Economic Behavior. Vol. 41, pp.192-205.

[18] Garlappi, L. †, (2001), Preemption Risk and the valuation of R\&D Ventures, Faculty of Commerce and Business Administration, The University of British Columbia, Canada

[19] Goldsmith R. E., Foxall, R. G., (2003), The measurement of Innovativeness, The International Handbook on Innovation edited by Larisa V. Shavinina, pp.321-330. Elsevier Science Ltd.

[20] Hacklin F., Raurich V., Marxt, C., (2004), How Incremental Innovation becomes Disruptive: The case of Technology Convergence, International Engineering Management Conference, IEEE. Pp.32-36.

[21] Huang, K. T., (1997), Capitalizing Collective Knowledge for Winning, Execution and Teamwork, Journal of Knowledge Management. Vol. 1, No. 2; pp. 149-156.

[22] Johannesson, M., Jonsson, B., Karlson, G., (1996), Outcome measurement in economic valuation. Health Economics. Vol. 5, pp.279-296.
[23] Karlz-Heinz, L., Bornemann, M., Schneider, U., (2002), Development and implementation of an intellectual capital Report for a Research Technology Organization. In Bontis, N., (Eds). World Congress on Intellectual Capital Readings. Butterworth, Heinemann, pp.266-285.

[24] Karl-Heinz, L., Campbell, W., (2004), Managing and reporting knowledge-based resources and processes in research organizations: specifics, lessons learned perspectives, Management Accounting Research, Volume 15, pp. 33-51. Elsevier

[25] Klose, Thomas, (1999), The contingent valuation method in health care, Health Policy, Vol.47, pp97-123.

[26] Lev, B., (2001), Intangibles, Management, Measuring and Reporting, Brookings Institution Press, Whashington, DC.

[27] McDermott, C., Handfield, R., (2000), Concurrent Development and Strategic Outsourcing: Do the Rules Change in Breakthrough Innovation? The Journal of High Technology Management Research, Vol. 11, Nr. 1, pp.35-57. Elsevier Science Inc.

[28] Mitchell, G., Hamilton, W., (1996), Managing R\&D as a strategic option. Research Technology Management, pp. 50-56.

[29] Moore S., (1986), Industry Sharing Research Costs, Journal of Metals. Edison Welding Institute. Vol. 38; No. 5; pp. 34-35.

[30] Muniesa, F., (2007), Market technology and the pragmatics of prices, Economy and Society. Vol. 36, No. 3; pp.377-395.

[31] Orduobadi, S., (2007), Opportunity cost of risks in evaluation of advanced technologies. International Journal of Innovation and Technology Management. Vol. 4, No. 3; pp.305-321. World Scientific Publishing Company.

[32] Park, Y, Park, G., (2004), A new method for technology valuation in monetary value: procedure and application. Technovation. Vol. 24; pp. 387-394. 
[33] Sheasley W. D., (2000), Taking an Options Approach to New Technology Development, Research Technology Management, Industrial Research Institute, NovemberDecember; pp.38-43.

[34] Smith, G. V., Parr, R. L., (2000), Valuation of Intellectual Property and Intangible Assets, 3rd ed., Wiley, New York, NY.

UNAM, (2004), Ciencia Estrategias de desarrollo del Subsistema de la Investigación Científica de la Universidad Nacional Autónoma de México.

[35] Van Triest, S., Vis, W., (2006), Valuing patents on cost reducing technology: A case study. International Journal of Production Economics. Vol. 105; pp.282-292. Elsevier B. V.

[36] Zettl, M., (2002), Valuing exploration and production projects by means of option pricing theory. International Journal of Production Economics. Vol. 78, pp.109-116. 


\section{Authors' Biography}
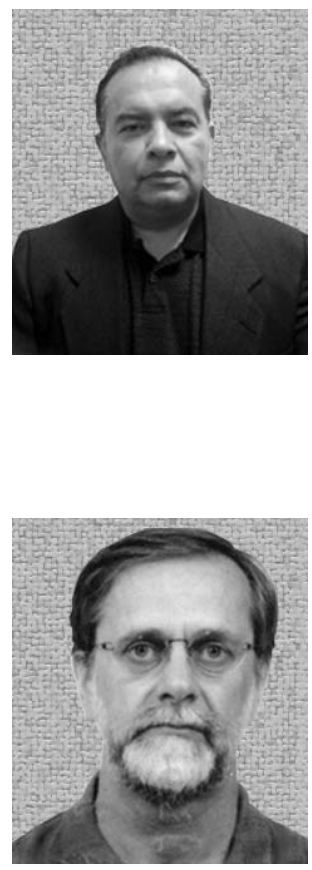

\section{Luis Roberto VEGA GONZÁLEZ}

He received his engineering master's degree in systems in 1987 and his master's degree in business and organizations in 2002, both from the Universidad Nacional Autónoma de México (UNAM). He has been technology management practitioner for integration and technology development projects since 1980 at the Mexican instrumentation and power industry and the UNAM. He is currently head of the liaison and technology transference office at the CCADET-UNAM.

\section{José Manuel SANIGER BLESA}

Dr.Saniger is a research professor at Centro de Ciencias Aplicadas y Desarrollo Tecnológico (CCADET) at the Universidad Nacional Autónoma de México (UNAM) and is currently general director of the CCADET. He received his PhD degree in chemical sciences from the Universidad Complutense de Madrid in 1988. His research areas of interest are nanostructured and catalytic materials, gas opto electrical sensors, and electro ceramics. 